\title{
We Need to Talk About Rationing: The Need to Normalize Discussion About Healthcare Rationing in a Post COVID-19 Era
}

\author{
Neera Bhatia
}

Received: 5 May 2020 / Accepted: 21 September 2020

(C) Journal of Bioethical Inquiry Pty Ltd. 2020

\begin{abstract}
The global COVID-19 pandemic has brought the issue of rationing finite healthcare resources to the fore. There has been much academic debate, media attention, and conversation in the homes of everyday individuals about the allocation of medical resources, diagnostic testing kits, ventilators, and personal protective equipment. Yet decisions to prioritize treatment for some individuals over others occur implicitly and explicitly in everyday practices. The pandemic has propelled the socially taboo and unavoidably prickly issue of healthcare rationing into the public spotlight — and as such, healthcare rationing demands ongoing public attention and transparent discussion. This article concludes that in the aftermath of COVID-19, policymakers should work towards normalizing rationing discussions by engaging in transparent and honest debate in the wider community and public domain. Further, injecting greater openness and objectivity into rationing decisions might go some way towards dismantling the societal taboo surrounding rationing in healthcare.
\end{abstract}

Keywords COVID-19 · Healthcare rationing .

Pandemic · Resources · Allocation · Law · Ethics · Public health

N. Bhatia $(\bowtie)$

Deakin University, School of Law, Melbourne, VIC 3125,

Australia

e-mail: neera.bhatia@deakin.edu.au

\section{Introduction}

The rationing of finite healthcare resources due to the COVID-19 global pandemic has become an acute topic of academic commentary and media coverage and a point of conversation in the homes of everyday citizens in countries with public healthcare systems (Longstaff 2020). Despite being ethically and legally fraught, immediate demands on the public healthcare system, infrastructure, and community services posed by the pandemic have resulted in healthcare rationing demanding serious consideration. Healthcare rationing has broadly focused on immediate needs such as the allocation of resources such as diagnostic testing kits, ICU (and hospital) beds, ventilators, and personal protective equipment (PPE). These issues have captured the attention of wider society, extending beyond the narrow scope of discussion amongst healthcare workers. The novel coronavirus has perhaps itself created a novel circumstance - bringing the issue of healthcare rationing to the fore. This may be the first time that many individuals have been compelled to engage in uncomfortable conversations about the prioritization of medical treatment. Moreover, for many, this may be their first time experiencing the death of a loved one and grieving in isolation without the support of others. Before COVID-19, healthcare rationing rarely received public attention. However, decisions to prioritize medical treatment for some individuals over others occur routinely.

This short article will briefly highlight circumstances where implicit and some explicit healthcare rationing decisions occur in everyday practices - broadly against 
an Australian backdrop, but where relevant, some U.K. examples will be drawn on. This will be followed by an exploration of some of the key ethical principles in the context of rationing and a brief consideration of the value that these principles ultimately provide during a time of global crisis when rationing decisions must be promptly made. This article argues that the pandemic has propelled the socially taboo and unavoidably prickly issue of healthcare rationing into the public spotlightand as such, healthcare rationing demands ongoing public attention and transparent discussion. This article concludes that in the aftermath of COVID-19, policymakers should work towards normalizing rationing discussions by engaging in transparent and honest debate in the wider community and public domain.

Observing the experience of countries that share similar public healthcare systems to its own, Australia has been preparing for the possibility of intensive care units (ICUs) becoming inundated with patients and its healthcare system becoming overburdened-where life or death decisions may need to be made. Some ethicists have also been grappling with the moral dilemma of whether healthcare workers should be given priority care if rationing becomes necessary (Sokol and Gray 2020). The following discussion briefly explores some of the ethical principles that relate to healthcare rationing.

\section{Ethical Principles for Resource Allocation: How Valuable Are They During a Pandemic?}

There are broad-ranging philosophical differences in the academic literature about how ethical principles should guide healthcare rationing as well as varying interpretation of the principles that relate to distributive justice in healthcare (Scheunemann and White 2011; Childress and Beauchamp 2009; White et al. 2009; Persad, Wertheimer, and Emanuel 2009). However, it is beyond the scope of this short article to discuss this issue at length.

The potential shortage of supply, and increasing demand for, medical resources due to COVID-19 present an intrinsically normative question: how can medical resources be equitably allocated during a crisis? While there are differing views on rationing, the central premise is that rationing relates to the denial of potentially beneficial medical resources or treatment due to shortage or scarcity (Truog et al. 2006).
Much of the academic debate concerns how appropriate ethical principles of distributive justice in healthcare are to maximize the best results with the least expense. For this article, the discussion below will briefly consider four broadly cited and recognized ethical principles applied to rationing in healthcare (Persad, Wertheimer, and Emanuel 2009; Scheunemann and White 2011).

1. Egalitarianism: treat patients equally

2. Utilitarianism: benefit the greatest number

3. Prioritarianism: favour the worst off (sickest first, youngest first)

4. Promoting and rewarding social usefulness: prioritize specific individuals to enable them to promote other important values or to reward them for having promoted these values

Each of the ethical principles above is problematic, raising a range of issues. Broadly, during a global pandemic, an egalitarian approach would encompass an equal opportunity to healthcare for all individuals. This approach often includes a "lottery" or "first come, first served" approach. Some supporters have stated that "each person's desire to stay alive should be regarded as of the same importance and deserving of the same respect as that of anyone else" (Harris 1970 quoted in Rivlin 2000, II2; Stein 2002). However, others have been more critical of this approach, suggesting that it is overly narrow. It also fails to take into consideration a range of factors that may contribute to systematic bias towards certain groups of society. Thus, an egalitarian approach lacks the equality and fairness that it aims to provide, for example, to those who may take longer to be admitted to hospital for treatment due to distance, disability, or socioeconomic status (Scheunemann and White 2011; Persad, Wertheimer, and Emanuel 2009). Utilitarian principles aim to maximize the number of lives saved. This might go some way towards resolving issues of ranking and judging the quality of individual lives - whereby each life is considered to be of value and there is no requirement to justify comparing lives to save them. Prioritarianism - attending to the worst off or sickest patients first also raises ethical concerns. Should the youngest (often vulnerable) patients be given priority treatment? Some have advocated that this "life cycle principle" should apply, given that the young have had the least opportunity to live through each of life's stages (Persad, Wertheimer, and Emanuel 2009; White 
et al. 2009). The concept of treating the sickest people first- "the rule of rescue" - has been deemed by some as "our moral response to the imminence of death [that] demands that we rescue the doomed" (Persad, Wertheimer, and Emanuel 2009, 424). Further, it would seem "intuitively obvious" that those who are the sickest or facing death be treated first (McKerlie 2001). Conversely, it might be claimed that it is counterproductive to treat those who are likely to be worst off, rather than those who are healthier and likely to recover unaided or who have a greater chance of improvement overall. Lastly, while social value cannot solely drive healthcare allocation (Harris 1987), it may be a consideration during a time of special circumstances, such as a pandemic, where an individual's social usefulness might be a factor in the prioritization of limited resources (Persad, Wertheimer, and Emanuel 2009, 425). This might include allocating healthcare resources towards an individual that contributes a significant value-for example, healthcare workers. By prioritizing their healthcare needs, we can benefit others. That is, if healthcare workers are treated as a priority, they will be in a position to treat other patients. Of course, this approach also has its flaws, amongst other things, this narrow approach arguably fails to recognize their intrinsic importance but rather the benefit that others can derive from them.

The ethical principles for rationing healthcare discussed above are wide-ranging and differ considerably. Invariably, grappling with unpalatable rationing decisions is a complex and ethically fraught task as it requires accommodating moral values and objectivity. Attempting to balance the priorities of patients with the greatest need and those patients with the greatest capacity to benefit from treatment also raises challenges. Importantly, questions about the fair distribution of scarce healthcare resources cannot be philosophized about at length when emergency rationing decisions about critical care are necessary. In a crisis such as COVID-19, rationing decisions become clearer. Acute decisions about who should be treated and who should not be treated need to be made swiftly with little time for deep moral reasoning.

Despite healthcare rationing becoming a more prominent discussion point during the global pandemic, healthcare rationing is not uncommon - although very rarely discussed publicly. The next section of this article explores some implicit and more explicit everyday practices of rationing that occur. The article then moves on to recommend that in a post-pandemic era (postCOVID-19), Australian policymakers should work towards normalizing rationing discussions in the wider community-beyond a pandemic response. Further, healthcare rationing should be a more transparent process for members of society to better understand its mechanisms and its rationale. This is ethically and socially important.

\section{Everyday Healthcare Rationing: Implicit and Explicit Decisions}

In most developed nations such as Australia, healthcare rationing continues to be a topic of controversy carrying long-standing societal taboo. COVID-19 has brought a sharp focus on rationing in academic literature and the popular press, especially in pandemic ravaged countries such as Italy (Beall 2020), the United States (Truog, Mitchell, and Daley 2020; Emanuel et al. 2020) and the United Kingdom (Wilkinson 2020), regardless of their healthcare models. Despite this, rationing in healthcare is not unique or uncommon. Finite healthcare budgets do not permit all patients to receive unlimited access to healthcare. Rationing decisions occur in a range of everyday situations both implicitly and explicitly (Strech, Synofzik, and Marckmann 2008; Halpern 2009).

Implicit methods of rationing healthcare can include deterring access to healthcare by imposing barriers such as the need for treatment referrals before a patient can access specialist care and the use of waiting lists for elective surgery. Other healthcare rationing methods can include setting eligibility criteria and thresholds for certain healthcare services. Routinely, patients are unaware that rationing decisions are being made that can have life and death consequences. Yet very rarely, if at all, do healthcare professionals discuss rationing with patients, partly due to the social taboo that is tethered to rationing.

An explicit type of rationing that occurs in the Australian context is government subsidized medication via the Pharmaceutical Benefits Scheme (PBS). Acute rationing determinations are made about the efficacy and cost of medical treatment, technology, and other interventions that will be subsidized by the government. Decisions are made about which medical treatments and medical interventions will be funded under the government scheme and those that will not. Perhaps the most explicit and well-recognized form of rationing is emergency department triage. A triage system works by categorizing 
incoming patients to an emergency department into groups using a scale. It offers a sharp illustration of the prioritization of healthcare based on the severity of need of need and/or likelihood of recovery.

\section{Implicit Rationing Decisions and the Law}

To date, the Australian and English courts have been reluctant to engage in any broad discussion about healthcare rationing in case law-presumably because notions of placing a monetary value on life are ethically and morally repugnant and because of the judiciary's disinclination to involve itself in political and policy decision-making. However, it could be argued that the courts play some role in implicit rationing decisions in cases where further treatment may be considered by some to be less than favourable. In this vein, implicit rationing decisions under the guise of nebulous concepts such as "futility," "best interests," and "quality of life" may be made. Concepts such as "medical futility" have been well explored and controversially noted as subjective and value laden. The English courts have touched on the issue of fair allocation of limited healthcare resources in cases concerning publicly funded treatment. These, however, received little attention $(\operatorname{Re} J(\mathrm{a}$ minor) (wardship: medical treatment) [1990] 3 All ER 930, 934; Airedale NHS Trust v Bland [1993] AC 789, 883; $R$ v Cambridge Health Authority Ex parte B [1995] 1 WLR 898). Recently, the High Court did, however, take a robust approach in addressing the issue of rationing healthcare by granting a hospital trust an injunction to remove an inpatient considered to be sufficiently well enough to be discharged to make a bed available for a COVID-19 patient (University College London Hospitals Foundation Trust v MB [2020] EWHC 882 (QB)).

This section of the article has provided some examples of implicit and explicit healthcare rationing in a range of different contexts. The following section will discuss the need for greater transparency in rationing discussions in the broader community in a postpandemic era.

\section{Transparent Rationing Discussions in a Post-Pandemic Era}

Healthcare rationing continues to be a socially taboo topic of discussion in liberal developed nations, with very little public, political, or professional (medical) debate. Some of the social taboo that surrounds rationing healthcare is polarized views in society about the allocation of resources. For example, it has been noted that discussion of explicit rationing of healthcare has been considered a cloak for potential euthanasia (Breyer 2013). Other members of society may interpret rationing more robustly or offensively if they consider that another person's life might be given greater value or worth than their own when rationing decisions are being made.

Despite the social taboo that pervades healthcare rationing, it is a necessary mechanism in public healthcare systems. Governments and policymakers need to continue to make tough rationing choices in fiscally constrained societies such as Australia. Indeed, rationing is likely to become even more critical in the aftermath of the pandemic as global economies begin to rebuild. During the pandemic, communities have placed a significant amount of trust in their elected leaders by accepting government healthcare advice and the suppression of physical liberties, otherwise unthinkable in pre-pandemic times (Archard 2020). In the aftermath of COVID-19, policymakers need to leverage this trust and goodwill to bring forward discussions about healthcare rationing.

Discussions about healthcare rationing should be advanced with greater transparency. While rationing occurs routinely, members of the public that access healthcare know very little about how rationing decisions are made. Post-COVID-19 rationing should be discussed more broadly in communities and decisions to ration healthcare should be made using (amongst others) (i) evidence-based (ii) economic evaluation tools that are nationally consistent (Martin 2015). Further, the allocation of healthcare resources should be discussed publicly and in terms that are easily understood by the diverse communities that public healthcare serves. Engaging in a transparent and honest discussion about rationing would benefit broader society in dispelling some of the social taboo and negative perceptions of rationing. Moreover, it would allow individuals to gain a better understanding of how public funds are allocated and distributed. Greater transparency in rationing would also improve the efficacy of the healthcare system more broadly. Discussions about rationing within communities and the public domain must shift from being an approach required as a pandemic response to forming part of our normal parlance in non-pandemic times. Normalizing discussion about rationing may also go 
some way to building greater public trust in the healthcare system and political system.

\section{Conclusion}

Healthcare rationing is complex. There is often a moral tension between efficacy and equity in healthcare. However, as rationing decisions can have life and death consequences, this article concludes that it is ethically and morally responsible to ensure that those accessing healthcare are provided with greater levels of transparency in how decision-making occurs not only for healthcare that individuals are able to access but more importantly for healthcare that they may be unable to access.

In this spirit, future policy and public discussion about healthcare rationing should work towards greater transparency about how rationing decisions are determined. Instead of implicit arbitrary rationing decisions, robust objective considerations should be made unambiguously and with greater transparency. This would go some way towards dismantling the societal taboo surrounding rationing in healthcare, making it less sensationalized as an emergency pandemic response.

\section{References}

Archard, D. 2020. Trustworthiness and "doing ethics." Nuffield Council on Bioethics Blog, April 20. https://www. nuffieldbioethics.org/blog/trustworthiness-and-doing-ethics.

Beall, A. 2020. The heart-wrenching choice of who lives and dies. $B B C$ Future, April 29. https://www.bbc. com/future/article/20200428-coronavirus-how-doctorschoose-who-lives-and-dies?

Breyer, F. 2013. Implicit versus explicit rationing of health services. CESifo DICE Report March 2013.

Childress, J., and T. Beauchamp. 2009. Principles of biomedical ethics, 6th ed. New York: Oxford University Press

Halpern, N.A. 2009. Can the costs of critical care be controlled? Current Opinion in Critical Care 15(6) 591-596.
Harris, J. 1970. The value of life: An introduction to medical ethics. London: Routledge and Keegan Paul.

-1987. QALYfying the value of life. Journal of Medical Ethics 13(3): 117-123.

Longstaff, S. 2020. Rationing life: COVID-19 triage and end of life care. The Ethics Centre, March 23. https://ethics.org. au/making-hard-choices-covid-19-triage/. Accessed May 3.

Martin, E. 2015. Rationing in healthcare. Deeble Institute Issues Brief, Australian Centre for Health Services Innovation, Queensland University of Technology.

McKerlie, D. 2001. Justice between the young and the old. Philosophy and Public Affairs 30(2): 152-177.

Persad, G., A. Wertheimer, and E.J. Emanuel. 2009. Principles for allocation of scarce medical interventions. The Lancet 373(9661): 423-431.

Rivlin, M.M. 2000. Why the fair innings argument is not persuasive. BMC Medical Ethics 1: 1.

Scheunemann, L.P., and D.B. White. 2011. The ethics and reality of rationing in medicine. Chest 140(6): 1625-1632.

Sokol, D., and B. Gray. 2020. Should we give priority care to healthcare workers in the covid-19 pandemic? BMJ Blog, April 1. https://blogs.bmj.com/bmj/2020/04/01/should-wegive-priority-care-to-healthcare-workers-in-the-covid-19pandemic/.

Stein, M.S. 2002. The distribution of life-saving medical resources: Equality, life expectancy, and choice behind the veil. Social Philosophy and Policy 19(2): 212-245.

Strech, D., M. Synofzik, and G. Marckmann. 2008. How physicians allocate scarce resources at the bedside: A systematic review of qualitative studies. Journal of Medicine and Philosophy 33(1): 80-99.

Truog, R.D., D.W. Brock, D.J. Cook, et al. 2006. Rationing in the intensive care unit. Critical Care Medicine 34(4): 958-963.

Truog, R.D., C. Mitchell, and G.Q. Daley. 2020. The toughest triage - allocating ventilators in a pandemic. New England Journal of Medicine 382(21): 1973-1975.

White, D.B., M.H. Katz, J.M. Luce, and B. Lo. 2009 Who should receive life support during a public health emergency? Using ethical principles to improve allocation decisions. Annals of Internal Medicine 150(2): 132-138.

Wilkinson, D. 2020. ICU triage in an impending crisis: Uncertainty, pre-emption and preparation. Journal of Medical Ethics 46(5): 287-288.

Publisher's note Springer Nature remains neutral with regard to jurisdictional claims in published maps and institutional affiliations. 